\title{
MCR-1 Gene Encoded Colistin-Resistant Escherichia coli in Raw Chicken Meat and Bean Sprouts in Malaysia
}

\author{
Erkihun Aklilu (iD and Kausalya Raman \\ Faculty of Veterinary Medicine, Universiti Malaysia Kelantan, Locked Bag 36, Kota Bharu, Kelantan, Malaysia \\ Correspondence should be addressed to Erkihun Aklilu; erkihun@umk.edu.my
}

Received 20 May 2020; Revised 3 June 2020; Accepted 1 July 2020; Published 28 July 2020

Academic Editor: Giuseppe Comi

Copyright (c) 2020 Erkihun Aklilu and Kausalya Raman. This is an open access article distributed under the Creative Commons Attribution License, which permits unrestricted use, distribution, and reproduction in any medium, provided the original work is properly cited.

\begin{abstract}
This study was conducted to detect the presence of colistin-resistant Escherichia coli (E. coli) in raw chicken meat and bean sprouts collected from local markets and to determine the antimicrobial resistance patterns of the E. coli isolates. A total of 100 samples, comprised of 50 raw chicken meat and 50 bean sprouts, were collected and processed. Kirby-Bauer method was used to determine the antimicrobial resistance patterns, and PCR amplification was used to detect $E$. coli species-specific and colistin resistance $(m c r-$ 1 and $m c r-2)$ genes. The results showed that $52.1 \%(12 / 23)$ of the E. coli isolated from raw chicken meat were positive for the colistin resistance encoding gene, $m c r-1$, whereas all the $E$. coli isolates from bean sprouts were negative for colistin resistance encoding genes. The findings show that chicken meat contaminated with colistin-resistant $E$. coli may pose public health risk to the consumers. Hence, prudent usage of antibiotics and hygienic handling of food items helps to prevent and combat the risks of spreading of colistin-resistant $E$. coli and the public health risks it may pose. More comprehensive and large-scale studies focusing on all the possible sources of colistin-resistant E. coli are recommended.
\end{abstract}

\section{Introduction}

Antimicrobial resistance (AMR) has been one of the alarming issues in recent decades. It has been a global threat drawing a global attention from several fields including medical science, veterinary, and agricultural fields. The rise and spread of AMR also led to enormous health and economic impacts. Though the constant warnings of the rise in antimicrobial resistance are not new, issues related to the impending threats of AMR were raised well before antimicrobials were established and used on a wider scale [1]. It did not take long before several pathogens developed resistance towards the available antimicrobials. Such incidences were fairly attributed to the rampant and irritational use of antimicrobial in human health, veterinary, and agricultural sectors. This in turn led to the emergence, evolution, and spread of numerous antibiotic-resistant bacteria.

Antimicrobial resistance in foodborne pathogens are of concern in recent days, especially when widely used in farms such as poultry production to control infectious diseases [2].
Hence, as antibiotic treatment persists, it will be one of the contributing factors to the emergence, selection, and spreading of antibiotic-resistant microorganisms in both veterinary and human medicine $[3,4]$. As it has been reported by several studies, infection caused by drug-resistant bacteria are much more difficult to be treated with the commonly available antibiotics [5]. Documented investigations have showed that the use of antibiotics can lead to the emergence and dissemination of resistant $E$. coli which in turn could pose public health risks [2]. Escherichia coli is a facultative anaerobic bacteria found in gastrointestinal tract of humans and animals. Generally, E. coli is a harmless microbe; however, there are pathogenic strains of E. coli that may cause different diseases in humans and animals [6]. Foods of plant origin, particularly vegetables, are prone to contamination by different species of bacteria. Such contaminations may happen by the use of insufficiently treated and contaminated water and fertilizers or through other contaminants during cultivation. Moreover, animals may also acquire different pathogenic bacteria through water or 
food contamination by human and other animals' wastes. The unhygienic handling of meat during processing has also been known to cause contamination of meats by various pathogenic bacteria [6].

The use of polymyxins (colistin) has been revived in recent years after the drug was almost abandoned decades ago due to its potential side effects. The revival of colistin is due to the fact that it emerged as the drug of choice in the face of the emergence of multidrug-resistant Gram-negative bacteria and the lack of potent new antibiotics to treat infections caused by these pathogens [7]. Moreover, colistin has been widely used in animal production industry to enhance productivity and control diseases. These in turn led to the emergence of colistin resistance in E. coli, and recently the first plasmid-mediated colistin resistance determinants, $m c r-1, m c r-2, m c r-3, m c r-4$, and $m c r-5$, have been identified in Enterobacteriaceae, mostly in E. coli [8]. The continued discovery of different colistin resistance mechanisms and determinants of resistance raises a serious concern as colistin has been considered as a last-resort medication for infections caused by Gram-negative bacteria that are resistant to multiple antibiotics.

In Malaysia, the availability of data and reports on the prevalence and antibiotic resistance patterns of E. coli strains, particularly as to the occurrence of colistin resistance in E. coli and other Enterobacteriaceae, is still not well documented and reported. As such it is crucial to create awareness of the existence of the pathogen in the food chain and subsequently its public health implications [9]. Moreover, to the best of our knowledge, there has never been any report on the occurrence of colistin-resistant $E$. coli in foodstuffs (chicken and vegetables) in the country, and there are very few similar investigations conducted elsewhere. Therefore, this study was conducted to determine the occurrence of colistin-resistant E. coli raw chicken meat and bean sprouts from wet markets, supermarkets, and retail shops from local markets and to determine the antimicrobial resistance patterns of the $E$. coli isolates towards selected antimicrobial agents including colistin.

\section{Materials and Methods}

2.1. Sample Collection and Preparation. One hundred $(n=100)$ raw food samples comprised of fifty $(n=50)$ raw chicken meat samples and fifty $(n=50)$ bean sprouts were collected from supermarkets, markets, and road side stalls of different locations in Kota Bharu. Each sample was placed into Ziploc bags and $10 \mathrm{~mL}$ normal saline water was added into each sample collection bag. The samples were brought to Bacteriology Laboratory, Faculty of Veterinary Medicine, Universiti Malaysia Kelantan in ice box, and aseptic techniques were used through to reduce contamination. All the samples were processed and subsequently subjected to various bacteriological, biochemical, and molecular tests in the laboratory. Buffer Peptone Water (BPW) (Oxoid, UK) was used as the primary preenrichment broth to permit recovery of bacteria after sublethal injury caused by heat, preservatives, or other processing techniques. MacConkey agar (Oxoid, UK) was used to isolate Enterobacteriaceae family. Eosin Methylene Blue (EMB) agar (Oxoid, UK) was used as a differential and selective medium to screen for the growth of E. coli.

2.2. Isolation and Identification of E. coli. After collection, all samples were homogenised using stomacher and $1 \mathrm{~mL}$ of the suspension was transferred into $10 \mathrm{~mL}$ buffered peptone water using disposable pipette and the homogenates were incubated at $37^{\circ} \mathrm{C}$ for $16-18 \mathrm{~h}$. After an overnight incubation in the preenrichment broth, a small amount of inoculum from BPW was transferred into MacConkey agar (Oxoid, UK) using a disposable pipette and streaked using a sterile wire loop. The inoculated plates samples were then incubated at $37^{\circ} \mathrm{C}$ for $24 \mathrm{~h}$. After inoculation and isolating colonies from MacConkey agar, EMB (Oxoid, UK) was further used for screening. Greenish metallic sheen colonies on EMB were transferred to Nutrient Agar to nourish and maintain the colonies before conducting biochemical test for E. coli. Further biochemical tests and Gram's staining were conducted to identify E. coli phenotypically.

2.3. Antimicrobial Susceptibility Test. All the confirmed E. coli isolates were subjected to antimicrobial susceptibility towards colistin, amoxycillin, gentamycin, and enrofloxacin using Kirby-Bauer methods. The guidelines of Clinical and Laboratory Standard Institute (CLSI) was used as a reference for the determination of susceptibility [10]. Mueller-Hinton Agar (MHA) (Oxoid, UK) was used for antimicrobial sensitivity test, and a previously identified colistin-resistant E. coli from our research was used for a quality control. A swab of single colony from nutrient agar plate was transferred into test tube with $10 \mathrm{~mL}$ containing $0.9 \%$ normal saline. Then, the turbidity of the samples was compared with $0.5 \%$ of McFarland standard and the suspension was uniformly streaked on MHA. After placing the antibiotic discs aseptically, the plates were incubated at $37^{\circ} \mathrm{C}$ for $24 \mathrm{~h}$ and the zone of inhibition was measured and interpreted according to CLSI guidelines [10].

\subsection{Detection of E. coli by Polymerase Chain Reaction (PCR)}

2.4.1. DNA Extraction and Primer Sequence. The genomic DNA was extracted using GF-1 Bacterial DNA Extraction Kit (Vivantis, Malaysia) following the manufacturer's recommendations. The primers used in this study for PCR identification of E. coli species and their resistance genes for colistin genes were selected based on previous studies. The PCR analysis was conducted for E. coli genes of family (Pho) with primers, Pho-F: 5'-GTGACAAAAGCCCGGACACCATAAATGC-3' and Pho-R: $5^{\prime}$-TACACTGTCATTACGTTGCGGATTTGGCG-3' ${ }^{\prime}$; colistin resistance genes mcr-1 (MCR-1F: 5'-CTCATGATGCAGCATACTTC-3' and MCR-1R: $5^{\prime}$-CGAATGGAGTGTGCGGTG-3') and mcr-2 (MCR-2F: 5'-TGTTGCTTGTGCCGATTGGA-3' and MCR-2R: $5^{\prime}$-AGATGGTATTGTTGGTTGCTG-3') [11-13]. Primers were obtained from Integrated DNA Technologies (Singapore). 


\subsection{Polymerase Chain Reaction (PCR) Amplification}

2.5.1. Amplification of E. coli-Specific Genes. As for the amplification procedure, the PCR mixtures were prepared for all samples that were phenotypically identified as E. coli. Two microlitres of bacterial DNA was amplified in $12.5 \mu \mathrm{L}$ of $2 \times$ Taq Master Mix (Vivantis, Malaysia) which consist of Taq DNA Polymerase $(0.05 \mu / \mu \mathrm{L}), 2 \times$ ViBuffer A, 0.4 Mm dNTPs and $3.0 \mathrm{Mm} \mathrm{MgCl} 2,8.5 \mu \mathrm{L}$ of nuclease-free water, and $1 \mu \mathrm{L}$ of each primer, respectively. PCR reaction for $E$. coli speciesspecific gene, the protocol was set as initial denaturation at $94^{\circ} \mathrm{C}$ for 2 minutes, final denaturation at $94^{\circ} \mathrm{C}$ for 1 minute, annealing at $56^{\circ} \mathrm{C}$ for 1 minute, extension at $72^{\circ} \mathrm{C}$ for 1 minute, cycle repeated at step $2\left(94^{\circ} \mathrm{C}\right.$ for 1 minute), followed by final extension at $72^{\circ} \mathrm{C}$ for 10 minutes and kept on hold at temperature $12^{\circ} \mathrm{C}$.

2.6. Amplification of Colistin Resistance Encoding Genes. As for amplification of colistin resistance genes, $2 \mu \mathrm{L}$ of bacterial DNA was added into $12.5 \mu \mathrm{L}$ of $2 \times$ Taq Master Mix (Vivantis, Malaysia) which consist of Taq DNA Polymerase $(0.05 \mu / \mu \mathrm{L}), 2 \times$ (ViBuffer A, 0.4 Mm dNTPs and $3.0 \mathrm{Mm}$ $\left.\mathrm{MgCl}_{2}\right), 8.5 \mu \mathrm{L}$ of nuclease-free water, and $1 \mu \mathrm{L}$ of each primer. The PCR protocol condition for MCR1F2/MCR1R2 primer pairs was with initial denaturation of DNA at $94^{\circ} \mathrm{C}$ for 3 minutes, followed by final denaturation at $94^{\circ} \mathrm{C}$ for 45 seconds, annealing at $60^{\circ} \mathrm{C}$ for 1 minute, and extension at $72^{\circ} \mathrm{C}$ for 3 minutes; then, the cycle was repeated 30 times at step 2 ( $94^{\circ} \mathrm{C}$ for 45 seconds), subsequently to final extension at $72^{\circ} \mathrm{C}$ for 4 minutes and finally, kept on hold at $4^{\circ} \mathrm{C}$. Moreover, PCR protocol condition for MCR2IF/MCR2IR was carried out at initial denaturation of $94^{\circ} \mathrm{C}$ for 3 minutes, final denaturation at $94^{\circ} \mathrm{C}$ for 2 minutes, annealing at $65^{\circ} \mathrm{C}$ for 2 minutes, extension at $72^{\circ} \mathrm{C}$ for 3 minutes, for 30 cycles, then, final extension at $72^{\circ} \mathrm{C}$ for 4 minutes before holding at $4^{\circ} \mathrm{C}$.

2.7. PCR Results Analysis. Analyses of the PCR products were conducted on $1.0 \%$ agarose gel (Agarose Vivantis, Malaysia) prepared in $60 \mathrm{~mL}$ of $1 \times \mathrm{TBE}$ Buffer added with $1.2 \mu \mathrm{L}$ of Midori Green (Nippon Genetics Europe, Germany) for $m c r-1$ gene. Meanwhile, as for E. coli, mcr-2 PCR products, it was analysed in $1.2 \%$ agarose gel prepared in $60 \mathrm{~mL}$ of $1 \times$ TBE Buffer added with $1.2 \mu \mathrm{L}$ of Midori Green. Then, electrophoresis was conducted at $80 \mathrm{~V}, 400 \mathrm{~A}$ for 45 minutes in a gel electrophoresis system for $m c r-1$, on the other hand, at $100 \mathrm{~V}, 400 \mathrm{~A}$ for 40 minutes for E. coli, mcr-2. As for the final step, the gel was photographed and analysed using Gel Doc ${ }^{\mathrm{TM}}$ EZ Imager (Bio-Rad, USA).

\section{Results}

3.1. Isolation and Identification of E. coli. Based on the routine phenotypic isolation and identification, presumptive E. coli isolates were detected in 54\% (27/50) of raw chicken meat and $20 \%(10 / 50)$ of the bean sprouts. Hence, the detection rate using phenotypic identification of $E$. coli in this study was $31 \%(31 / 100)$.
3.2. Antimicrobial Sensitivity Test. As for AST results, four antibiotics (amoxycillin/clavulanic acid, colistin, enrofloxacin, and gentamicin) were used, and based on the sensitivity of $E$. coli isolates from raw chicken meat, the highest number of samples showed resistance towards amoxycillin, followed with enrofloxacin, colistin, and gentamicin. Meanwhile, as for the bean sprouts, most of the resistance detected was against amoxycillin and colistin; however, no resistance towards enrofloxacin and gentamicin was detected. Moreover, MDR E. coli were also detected with resistance ranging from two to all antibiotics tested. The outcome of the determination of MDR isolates observed mostly in raw chicken meat as compared to bean sprouts with none of the isolates showing MDR. Tables 1 and 2 show the overall AST results and MDR status of the E. coli isolates from both food samples.

\subsection{Molecular Identification}

3.3.1. PCR Results for E. coli-Specific mcr-1 and mcr-2 Genes Detection. Out of 31 presumptive E. coli isolates, 29 samples were positive for the presence of $E$. coli species-specific gene at $903 \mathrm{bp}$. Out of these 29 samples, 23 were from raw chicken meat and 6 were from bean sprouts. As for the detection of the resistance gene $m c r$ - 1 , all the 29 samples were confirmed to be $E$. coli through PCR; 12 isolates were positive for resistance gene with the presence of amplification products at $1674 \mathrm{bp}$. All the 12 samples were from raw chicken meat and none of the isolates from bean sprouts samples showed the presence of the gene encoding for colistin resistance. Meanwhile, all the E. coli isolates from both food samples were negative for $m c r-2$ gene.

\section{Discussions}

Based on the results from routine bacterial culture and biochemical results, $46 \%(23 / 50)$ and $12 \%(6 / 50)$ of raw chicken meat and bean sprouts were, respectively, positive for E. coli. E. coli is commensally present in all warmblooded animals at the enteric regions; hence, a high percentage of $E$. coli isolates to be obtained in raw chicken meat as compared to bean sprouts might be due to the higher probability of contamination of chicken meat by intestinal contents during processing and handling of chicken meat. Handling of meat and animal carcasses, cross contamination from soil, processing instruments, and the use of contaminated water for washing purpose can be major sources of contamination of chicken meat [14]. In addition to E. coli, other members of the Enterobacteriaceae family including Enterobacter aerogenes and Klebsiella pneumoniae were also identified in this research. Previous studies have reported that presence of E. coli in food is often considered as an indicator for the presence of other pathogenic bacteria in the respective food items [15]. As to the $24 \%$ detection rate of $E$. coli in bean sprouts in this study, the results may imply the high occurrence of contaminations of bean sprouts possibly through usage of contaminated water or untreated sewage water used as fertilizers that could possibly be mixed with manure of animals [15]. Several studies have reported 
TABLE 1: Antimicrobial susceptibility patterns of E. coli $(n=29)$ isolates from raw chicken meat and bean sprouts.

\begin{tabular}{|c|c|c|c|c|c|c|}
\hline \multirow{3}{*}{ Antibiotic disc (concentration, $\mu \mathrm{g}$ ) } & \multicolumn{6}{|c|}{ Types of samples } \\
\hline & \multicolumn{3}{|c|}{ Raw chicken meat $(n=23)$} & \multicolumn{3}{|c|}{ Bean sprouts $(n=6)$} \\
\hline & $\begin{array}{c}R \\
\text { No. }(\%)\end{array}$ & $\begin{array}{c}I \\
\text { No. }(\%)\end{array}$ & $\begin{array}{c}S \\
\text { No. }(\%)\end{array}$ & $\begin{array}{c}R \\
\text { No. }(\%)\end{array}$ & $\begin{array}{c}I \\
\text { No. }(\%)\end{array}$ & $\begin{array}{c}S \\
\text { No. }(\%)\end{array}$ \\
\hline AML $(10 \mu \mathrm{g})$ & $22(95.7)$ & $0(0)$ & $1(4.3)$ & $2(33.3)$ & $3(50.0)$ & $1(16.7)$ \\
\hline CT $(10 \mu \mathrm{g})$ & $9(39.1)$ & - & $14(60.9)$ & $1(16.7)$ & - & $5(83.3)$ \\
\hline ENR $(5 \mu \mathrm{g})$ & $14(60.9)$ & $7(30.4)$ & $2(8.7)$ & 0 & $0(0)$ & $6(100)$ \\
\hline $\mathrm{CN}(10 \mu \mathrm{g})$ & $7(30.4)$ & $1(4.3)$ & $15(65.2)$ & $0(0)$ & $0(0)$ & $6(100)$ \\
\hline
\end{tabular}

AML: amoxycillin/clavulanic acid, ENR: enrofloxacin, CN: gentamicin, and CT: colistin.

TABLe 2: Multidrug-resistant (MDR) isolates of E. coli from raw chicken meat and bean sprouts.

\begin{tabular}{lcc}
\hline Antibiotic drugs as MDR & \multicolumn{2}{c}{ Source of MDR isolates } \\
& Raw chicken meat no. (\%) & Bean sprouts no. (\%) \\
\hline AML, ENR & $14(26.4)$ & $0(0)$ \\
AML, CT & $9(17.0)$ & $0(0)$ \\
AML, CN & $8(15.1)$ & $0(0)$ \\
AML, ENR, CT & $7(13.2)$ & $0(0)$ \\
AML, ENR, CN & $6(11.3)$ & $0(0)$ \\
AML, CT, CN & $5(9.4)$ & $0(0)$ \\
AML, ENR, CT, CN & $4(7.5)$ & 0 \\
Total & 53 & 0 \\
\hline
\end{tabular}

AML: amoxycillin/clavulanic acid, ENR: enrofloxacin, CN: gentamicin, and CT: colistin.

foodborne pathogens isolated from agricultural products including vegetables and fruits. Likewise, these studies have also linked occurrence of food poisoning cases to contaminated vegetables and fruits $[16,17]$.

The AST results for $E$. coli isolates from raw chicken meat revealed that most of the isolates were resistant to amoxycillin $(95.7 \%)$ followed by enrofloxacin $(60.9 \%)$ and colistin (39.1\%). These results show that the E. coli isolated from poultry meat sold in local markets are multidrug-resistant. Although some of the isolates appeared to be susceptible to colistin upon disc diffusion test, the same isolates were found to be positive for colistin resistance encoding gene, $m c r-1$. This discrepancy might be attributed to the less reliability of AST determination by disc diffusion test as compared to PCR which is the gold standard for detection of antimicrobial resistant bacteria [18]. It has also been reported that disc diffusion, although it is simple and easy to perform and interpret, is less reliable as compared to agar dilution and determination of minimum inhibitory concentration [19-21]. The emergence of antibiotics resistance in bacteria may occur as a result of horizontal transmission of resistance genes and transmissible elements like plasmids among bacterial species and strains [22]. Moreover, different species of bacteria are able to pass their resistance genes to their offspring by replication or to related bacteria through conjugation [23]. In E. coli, acquisition of resistance genes occurs through exchanges of resistance genes through conjugation [24]. It has also been reported that multiple antibiotic resistance may be acquired through mobile genetic elements such as plasmids, transposons, and class 1 integrons [25].

Meanwhile, PCR detection results confirmed that 29/31 $(93.55 \%)$ of phenotypically identified isolates were confirmed to be E. coli. This difference between PCR and routine bacteriology results shows that molecular methods are superior to phenotypical detection for the identification of bacterial species. As for the detection of colistin resistance, $41.38 \%(12 / 29)$ E. coli isolates from raw chicken meat showed positive results for resistance gene, $m c r-1$. This finding confirms the presence of colistin resistance in local $E$. coli isolates from raw chicken meat sold at local markets. The results may also imply that the colistin-resistant $E$. coli might have originated from the source, i.e., poultry farms, and the possible emergence and spread of colistin resistance in poultry farms and beyond. The detection rate recorded in the current study is higher compared to other similar studies conducted elsewhere. A similar study conducted in Brazil, South America, reported lower detection rate (19.5\%) of colistin-resistant $E$. coli harbouring $m c r-1$ genes in chicken meat samples collected from local markets in Sao Paulo [26]. Another study from Pakistan conducted on screening of 100 healthy broiler chicken reported a much lower prevalence of $8 \%(8 / 100)$ colistin-resistant E. coli [27]. The emergence and spread of colistin-resistant $E$. coli in farm animals and animal products such as chicken meat raises a serious public health concern that needs to be addressed with a sense of urgency. Colistin being a last-resort antibiotic for the treatment of infections in humans caused by Gram-negative bacteria like E. coli, the occurrence and spread of colistin resistance in animals and its detection in food is concerning. In this study, the resistance gene, $m c r-2$, was not detected. In conclusion, it is very concerning and is an alarming issue that colistin resistance is emerging and spreading in food animals and their products. The current findings also revealed that colistin-resistant $E$. coli are prevalent in chicken meat intended for human consumption. These 
findings underscore the importance and urgency to counter the emergence and spread of these resistant bacteria. Further comprehensive studies including molecular typing, virulence genes profiling, and tracing of potential sources of colistin-resistant E. coli are recommended.

\section{Data Availability}

All the required data are included in the manuscript.

\section{Conflicts of Interest}

The authors declare that they have no conflicts of interest regarding the publication of this paper.

\section{Acknowledgments}

The authors would like to acknowledge the administration and laboratory technicians in Bacteriology and Molecular Biology Laboratories at the Faculty of Veterinary Medicine, Universiti Malaysia Kelantan, for their support.

\section{References}

[1] A. Huttner, S. Harbarth, J. Carlet et al., "Antimicrobial resistance: a global view from the 2013 world healthcare-associated infections forum," Antimicrobial Resistance and Infection Control, vol. 2, no. 1, p. 31, 2013.

[2] M. A. Akond, S. Alam, S. M. R. Hasan, S. Mubassara, S. N. Uddin, and M. Shirin, "Bacterial contaminants in carbonated soft drinks sold in Bangladesh markets," International Journal of Food Microbiology, vol. 130, no. 2, pp. 156-158, 2009.

[3] R. Cantón and M.-I. Morosini, "Emergence and spread of antibiotic resistance following exposure to antibiotics," FEMS Microbiology Reviews, vol. 35, no. 5, pp. 977-991, 2011.

[4] V. Economou and P. Gousia, "Agriculture and food animals as a source of antimicrobial-resistant bacteria," Infection and Drug Resistance, vol. 8, pp. 49-61, 2015.

[5] S. F. Altekruse, "Emerging foodborne diseases," Emerging Infectious Diseases, vol. 3, no. 3, pp. 285-293, 1997.

[6] A. K. Biswas, N. Kondaiah, A. S. R. Anjaneyulu, and P. K. Mandal, "Causes, concerns, consequences and control of microbial contaminants in meat-A review," International Journal of Meat Science, vol. 1, no. 1, pp. 27-35, 2011.

[7] M. E. Falagas, S. K. Kasiakou, and L. D. Saravolatz, "Colistin: the revival of polymyxins for the management of multidrugresistant gram-negative bacterial infections," Clinical Infectious Diseases, vol. 40, no. 9, pp. 1333-1341, 2005.

[8] A. R. Rebelo, V. Bortolaia, J. S. Kjeldgaard et al., "Multiplex PCR for detection of plasmid-mediated colistin resistance determinants, $m c r-1, m c r-2, m c r-3, m c r-4$ and $m c r-5$ for surveillance purposes," Euro Surveillance, vol. 23, no. 6, p. 17, 2018.

[9] A. Frederick, "Escherichia coli, it prevalence and antibiotic resistant in Malaysia: a mini review," Microbiology Journal, vol. 1, no. 2, pp. 47-53, 2011.

[10] Clinical and Laboratory Standards Institute (CLSI), Performance Standards for Antimicrobial Susceptibility Testing, Twenty-Third Informational Supplement 2013, M100-S23.

[11] S. S. Elnahriry, H. O. Khalifa, A. M. Soliman et al., "Emergence of plasmid-mediated colistin resistance genemcr-1in a clinical
Escherichia coli isolate from Egypt," Antimicrobial Agents and Chemotherapy, vol. 60, no. 5, pp. 3249-3250, 2016.

[12] N. Liassine, L. Assouvie, M.-C. Descombes et al., "Very low prevalence of $m c r-1 / m c r-2$ plasmid-mediated colistin resistance in urinary tract Enterobacteriaceae in Switzerland," International Journal of Infectious Diseases, vol. 51, pp. 4-5, 2016.

[13] R. Y. C. Kong, C. L. So, W. F. Law, and R. S. S. Wu, "A sensitive and versatile multiplex PCR system for the rapid detection of enterotoxigenic (ETEC), enterohaemorrhagic (EHEC) and enteropathogenic (EPEC) strains of Escherichia coli," Marine Pollution Bulletin, vol. 38, no. 12, pp. 1207-1215, 1999.

[14] A. Rouger, O. Tresse, and M. Zagorec, "Bacterial contaminants of poultry meat: sources, species, and dynamics," Microorganisms, vol. 5, no. 3, p. 50, 2017.

[15] M. U. Rasheed, N. Thajuddin, P. Ahamed, Z. Teklemariam, and K. Jamil, "Antimicrobial drug resistance in strains of Escherichia coli isolated from food sources," Revista do Instituto de Medicina Tropical de São Paulo, vol. 56, no. 4, pp. 341-346, 2014.

[16] S. K. Mritunjay and V. Kumar, "A study on prevalence of microbial contamination on the surface of raw salad vegetables," 3 Biotech, vol. 7, no. 1, p. 13, 2017.

[17] M. Steele and J. Odumeru, "Irrigation water as source of foodborne pathogens on fruit and vegetables," Journal of Food Protection, vol. 67, no. 12, pp. 2839-2849, 2004.

[18] L. B. Reller, M. Weinstein, J. H. Jorgensen, and M. J. Ferraro, "Antimicrobial susceptibility testing: a review of general principles and contemporary practices," Clinical Infectious Diseases, vol. 49, no. 11, pp. 1749-1755, 2009.

[19] P. J. Taormina, L. R. Beuchat, and L. Slutsker, "Infections associated with eating seed sprouts: an international concern," Emerging Infectious Diseases, vol. 5, no. 5, pp. 626-634, 1999.

[20] H. Khalili, R. Soltani, S. Negahban, A. Abdollahi, and K. Gholami, "Reliability of disk diffusion test results for the antimicrobial susceptibility testing of nosocomial grampositive microorganisms: is E-test method better?" IJPR, vol. 11, pp. 559-563, 2012.

[21] M. Lehtopolku, P. Kotilainen, P. Puukka et al., "Inaccuracy of the disk diffusion method compared with the agar dilution method for susceptibility testing of Campylobacter spp," Journal of Clinical Microbiology, vol. 50, no. 1, pp. 52-56, 2012.

[22] M. Schroeder, B. Brooks, and A. Brooks, "The complex relationship between virulence and antibiotic resistance," Genes, vol. 8, no. 1, p. 39, 2017.

[23] C. J. H. von Wintersdorff, J. Penders, J. M. van Niekerk et al., "Dissemination of antimicrobial resistance in microbial ecosystems through horizontal gene transfer," Frontiers in Microbiology, vol. 7, p. 173, 2016.

[24] S. Domingues, K. M. Nielsen, and G. J. da Silva, "Various pathways leading to the acquisition of antibiotic resistance by natural transformation," Mobile Genetic Elements, vol. 2, no. 6, pp. 257-260, 2012.

[25] S. R. Partridge, S. M. Kwong, N. Firth, and S. O. Jensen, "Mobile genetic elements associated with antimicrobial resistance," Clinical Microbiology Reviews, vol. 31, no. 4, 17 pages, 2018.

[26] D. F. Monte, A. Mem, M. R. Fernandes et al., "Chicken meat as a reservoir of colistin-resistant Escherichia coli strains carrying mcr-1 genes in South America," Antimicrobial Agents and Chemotherapy, vol. 61, no. 5, 16 pages, 2017.

[27] J. Lv, M. Mohsin, S Lei et al., "Discovery of a mcr-1-bearing plasmid in commensal colistin-resistant Escherichia coli from healthy broilers in Faisalabad, Pakistan," Virulence, vol. 9, no. 1, pp. 994-999, 2018. 